\section{Identification of Intracultivar Genetic Heterogeneity in Cranberry Using Silver-stained RAPDs}

\author{
Richard G. Novy and Nicholi Vorsa ${ }^{1}$ \\ Blueberry and Cranberry Research Center, Rutgers University, Chatsworth, \\ NJ 08019
}

\begin{abstract}
Additional index words. Vaccinium macrocarpon, cultivar misclassification, DNA fingerprint, germplasm
\end{abstract}

\begin{abstract}
Cranberry (Vaccinium macrocarpon Ait.) has few qualitative, morphological characteristics that can be used to reliably distinguish among cultivars. Fifty-two silverstained random amplified polymorphic DNAs (ssRAPDs) were used to assess genetic heterogeneity and relatedness within accessions of four major cranberry cultivars ('Early Black', 'Howes', 'McFarlin', and 'Searles'). Rather than being represented by one genotype, as might be expected in an asexually propagated crop, each cultivar was represented by multiple genotypes, which in many cases did not appear to be closely related to one another. The intracultivar heterogeneity was often so extreme that clonal representatives of a cultivar would group with representatives of other cultivars following cluster analysis. Of the total SsRAPD variation, $9.7 \%$ could be attributed to variation among the four cultivar groups and $\mathbf{9 0 . 3 \%}$ to variation within the cultivars. 'Howes' was the only cultivar in which a consensus DNA fingerprint among regional representatives could be identified.
\end{abstract}

The cultivated cranberry is a woody perennial represented by 139 clonal cultivars (Eck, 1990). Most of these cultivars were selected from native cranberry bog populations 100 to 150 years ago. Since their initial selection, the identities and trueness-to-type of many cultivars have been obscured due to various biological and cultural factors. Although a cranberry planting initially may be composed of one cultivar, represented by a single genotype, the potential exists for the establishment of volunteer seedlings and native clones during the decades that a planting is productive. Once established, these genetic variants have the potential to spread vegetatively throughout the planting by stolons, creating a heterogeneous population. Traditionally, new cranberry plantings are established from stolons raked from a producing bog. Plantings established with stolons obtained from a genetically diverse population have the potential to evolve genetic compositions that differ from the original cultivar planting. As a result, variability might be expected for horticultural traits within the bogs of a cultivar as a consequence of the presence, absence, or proportion of genotypes represented within each bog.

Received for publication 13 Dec. 1995. Accepted for publication 14 Feb. 1995. New Jersey Agricultural Expt. Station publication D-12163-7-94 supported by state funds, the U.S. Hatch Act, CSRS grant 93-34155-8382, and Ocean Spray Cranberries. We thank Carin Hollis for her assistance in the laboratory and Carol Kobak and Peter Smouse for developing and providing the software programs BANDAID and FINDSPACE. The cost of publishing this paper was defrayed in part by the payment of page charges. Under postal regulations, this paper therefore must be hereby marked advertisement solely to indicate this fact.

${ }^{1}$ To whom reprint requests should be addressed.
The paucity of qualitative morphological descriptors in cranberry also contributes to cultivar misrepresentation (Novy et al., 1994). Descriptions of cranberry cultivars rely largely on berry morphology [e.g., fruit size, shape, color, and the presence of cuticular wax (bloom)]. These traits are influenced by environmental conditions, making them unreliable for effectively distinguishing among cranberry cultivars.

Molecular markers, such as isozymes, have been used in assessing genetic diversity in cranberry (L.P. Bruederle et al., unpublished data). Twenty-three putative Mendelian loci were identified using isozymes and were used for calculating genetic distance values between 10 native populations of cranberry distributed from Wisconsin to Massachusetts and south to Delaware. Genetic identities obtained from pairwise comparisons of the populations ranged from 0.977 to 1.000 , indicating that little genetic differentiation had occurred between the populations. Relative to other plant species, the total genetic diversity within cranberry was low $\left(\mathrm{H}_{\mathrm{t}}=0.048\right)$, thereby limiting the effectiveness of isozymes for assessing genetic diversity and cultivar identification.

Random amplified polymorphic DNA (RAPD) markers separated in polyacrylamide gels and visualized by silver-stain are used as an alternative to isozymes. As previously reported (Caetano-Anolles et al., 1991, 1992; Huff and Bara, 1993; Huff et al., 1993, 1994; Novy et al., 1994), the increased resolution of polyacrylamide gels in conjunction with the 2to 5-fold increased sensitivity of silver staining compared to ethidium bromide (Bio-Rad Laboratories, silver-stain manual) provides reproducible molecular markers. The increased sensitivity of silver stain for the visualization of RAPDs reduces the potential for the misscoring of bands, especially in situations involving epistatic interactions between priming sites (Heun and Helentjaris, 1993).

A total of 22 cranberry cultivars were analyzed using 66 silver-stained RAPDs (ssRAPDs) generated by 22 decamer primers (Novy et al., 1994). Rather than the expected 22 unique ssRAPD profiles, only 17 were identified. Fourteen cultivars had unique ssRAPD profiles, and the remaining eight were represented by three ssRAPD profiles. Permutational analyses of the data indicated that identical band profiles among cultivars were examples of cultivar misclassification, resulting in the representation of a genotype by several cultivar names. Identifying cultivar misclassifications emphasizes the difficulty in distinguishing among cranberry cultivars solely based on morphological descriptors. These findings in cranberry are analogous to observations in clonally propagated vetiver grass [Vetiveria zizanioides (L.) Nash ex Small], in which two seemingly unique accessions were found to be represented by the same genotype based on RAPDs (Kresovich et al., 1994).

Intracultivar variability, whether due to cultivar misclassification or the establishment of genetic variants in a cultivar bog, confounds the results of cranberry research studies and can create redundancy and confusion in germplasm collections. Intracultivar variation also may have serious economic ramifications for growers who unknowingly establish cranberry bogs with less productive genotypes of a cultivar. 'Howes', 'Early Black', 'McFarlin', and 'Searles', collectively called the "Big Four," account for $>80 \%$ of the total commercial cranberry hectarage in North America (Eck, 1990). All four cultivars were selected from native cranberry populations before 1900 and have been used in producing first-generation hybrids (Eck, 1990). Our objectives were 1) to use ssRAPDs to obtain an initial assessment of the degree of intracultivar genetic variation within the Big Four cranberry cultivars using various regional accessions and putative genetic variants and 2) to ascertain if identical ssRAPD profiles could be found among regional representatives of a cultivar, thereby identifying a ssRAPD “consensus” fingerprint that would typify that cultivar. These data also would be useful for germplasm evaluation and characterization in cranberry.

\section{Materials and Methods}

Plant material. The representatives and putative variants of 'Howes', 'Early Black', 'Searles', and 'McFarlin' (Table 1) were single vines obtained from various bog and experimental plantings, except for Early Black-NJ $\# 1$ and \#2, which originated from the same bog. Leaves from the 23 clones were collected from greenhouse-grown plants in May 1993, frozen in liquid $\mathrm{N}$, and stored at $-73 \mathrm{C}$.

DNA extraction and quantification. DNA from four clones, McFarlin-NJ, Howes-NJ \#3, Early Black-NJ \#5, and Searles-WI, was extracted in May 1993 using Rowland and Nguyen's (1993) procedure without the poly- 
ethylene glycol DNA-precipitation step. DNA of the remaining 19 clones was extracted from frozen leaf material in July 1993 using the minipreparation procedure described by Stewart and Via (1993). We modified this procedure by grinding liquid-N-cooled leaf material with $1.5-\mathrm{ml}$ polypropylene mixers (Kontes, Vineland, N.J.) before adding extraction buffer at 65C (ascorbic acid and diethyldithiocarbamic acid were not included in the buffer). DNA pellets were dissolved in $50 \mu l$ of a modified TE [Tris(hydroxymethyl)amino-methane/ethylendiaminetetraacetic acid (EDTA)] buffer consisting of 0.1 mM, rather than 1.0 mm EDTA. Two microliters of ribonuclease $\mathrm{A}\left(10 \mathrm{mg} \cdot \mathrm{ml}^{-1}\right)$ then were added, and tubes were incubated at $37 \mathrm{C}$ for 30 min. DNA concentrations were quantified with a TKO-100 fluorometer (Hoefer Scientific Instruments, San Francisco) and diluted to a standard $5 \mathrm{ng} \cdot \mu \mathrm{l}^{-1}$.

Amplification, scoring, and analysis of ssRAPDs. DNA amplification, electrophoresis, silver staining, band scoring, and data analysis were conducted as described by Novy et al. (1994). The Euclidean metric of Excoffier et al. (1992) was used in the calculation of genetic dissimilarity estimates between all pairs of individuals. This metric can be defined as $\mathrm{E}_{\mathrm{xy}}=n\left[1-\left(2 n_{\mathrm{xy}} / 2 n\right)\right]$, where $\mathrm{E}_{\mathrm{xy}}$ is the Euclidean distance between individuals $\mathrm{x}$ and $\mathrm{y}, n$ is the total number of polymorphic ssRAPD sites, and $2 n_{\mathrm{xy}}$ is the number of ssRAPDS jointly present or absent in the two individuals. This distance estimate is analogous to a summation of ssRAPD differences between the two individuals. The matrix of genetic dissimilarity values was used in sequential, agglomerative, hierarchical, and nested cluster analysis using the unweighted pair-group linkage method. The analysis of molecular variance (AMOVA) procedure (Excoffier et al., 1992) was used to estimate variance components for the ssRAPD data and to partition it between and within the four cultivars. Calculations were conducted with the WINAMOVA program provided by L. Excoffier (Dept. of Anthropology and Ecology, Univ. of Geneva, Geneva, Switzerland).

The software programs BANDAID and FINDSPACE were used for ssRAPD analysis (Kobak and Smouse, unpublished). BANDAID identifies the proportion of clones in a given grouping that have a ssRAPD band and also flags those individuals with unique ssRAPDs bands. FINDSPACE was used to identify "associated" or "nonindependent" ssRAPDs (see Appendix 2, Novy et al., 1994). Both software programs are available on request from Carol Kobak, 6Edgehill Rd., West Orange, NJ 07052.

The ssRAPD analysis of the 23 cranberry clones was conducted with 12 decamer primers-OPA-01, 02, 04, 05, 07 to 11 , and 17 (Operon Technologies, Almeda, Calif.) and U.B.C. 471 and 472 (Univ. of British Columbia Biotechnology Laboratory, Vancouver, Canada). Eleven of these primers were a subset of those used by Novy et al. (1994) and (along with the 12th primer used in this study) were known to provide informative and reproducible ssRAPDs among DNA extractions and across DNA amplifications when visual- ized in silver-stained acrylamide gels. To avoid the possibility of bias during band scoring, clones were not grouped by cultivar but were randomized before placing in the thermocycler; this random ordering then was maintained in the loading of the gels.

\section{Results}

The ssRAPD markers. Twelve primers generated 116 scorable bands, of which $52(45 \%)$ were polymorphic. A range of 1 to 14 amplified bands per primer was observed, with an average of 9.7 bands. Examples of the variability in the ssRAPD profiles of the cultivar representatives and their reproducibility across DNA extractions and amplifications are shown (Fig. 1).

Seven examples of nonindependence among ssRAPDs were identified (i.e., the presence or absence of an amplified band within the ssRAPD profiles positively correlated with the presence or absence of another band). This association among bands suggested that they were either tightly linked with one another, examples of associated heteroduplex bands, or that a primer-recognition site was inside a larger template sequence (Novy et al., 1994). Eighty-six percent of the cases of nonindependence occurred within a given primer. Genetic dissimilarity estimates were calculated using the original data and a modified version with nonindependent bands removed. The correlation coefficient between the two data sets was 0.99 . This high value indicated that the nonindependent ssRAPDs had no substantial impact on the genetic dissimilarity values obtained and the subsequent cluster analysis. Based on this finding, the complete data set was used.

Dissimilarity values and cluster analysis. The matrix of genetic dissimilarity values was calculated for 52 ssRAPDs (Table 2). Clones differed by an average of 16 bands with a range of 0 to 26. The dendrogram (Fig. 2) generated from these dissimilarity values shows that the 23 clones are represented by 14 ssRAPD phenotypes. Rather than four discrete clusters corresponding to each of the four cultivars and their variants, a wide range of variability existed. In several cases, it seemed that different accessions of a given cultivar were not even closely related. Conversely, these were two examples of different cultivars with identical

Table 1. Representative and variant clones of 'McFarlin', 'Howes', 'Early Black', and 'Searles' used in silver-stained random amplified polymorphic DNA analysis.

\begin{tabular}{|c|c|c|c|}
\hline$\overline{\text { Clone }}$ & Identification $^{z}$ & State of origin & Source/comments \\
\hline \multicolumn{4}{|c|}{ McFarlin accessions } \\
\hline Bain & US92-6-1 & Wisconsin & $\begin{array}{l}\text { Selection made by H.F. Bain- } \\
\text { considered to be true 'Mcfarlin', }\end{array}$ \\
\hline Rezin & US92-9-2 & Wisconsin & Selection from commercial planting \\
\hline OR & US89-6 & Oregon & $\begin{array}{l}\text { U.S. Dept. of Agriculture Clonal } \\
\text { Repository }\end{array}$ \\
\hline WA \#1 & US93-89 & Washington & $\begin{array}{l}\text { A poor-producing commercial } \\
\text { planting, Grayland district }\end{array}$ \\
\hline WA \#2 & US93-93 & Washington & $\begin{array}{l}\text { A commerical planting of true } \\
\text { 'Mcfarlin', Grayland district }\end{array}$ \\
\hline NJ & US94-7 & New Jersey & Rutgers experimental bog \\
\hline \multicolumn{4}{|c|}{ Howes accessions } \\
\hline NJ \#1 & US93-126 & New Jersey & $\begin{array}{l}\text { Chatsworth Cranberry Co., Bog A-3, } \\
\text { Burlington County }\end{array}$ \\
\hline $\mathrm{NJ} \# 2$ & US93-138 & New Jersey & $\begin{array}{l}\text { Haines and Haines, Inc.; Bog 2; } \\
\text { Burlington County }\end{array}$ \\
\hline $\mathrm{NJ} \# 3$ & US94-8 & New Jersey & Rutgers experimental bog \\
\hline Smalley & US92-42 & Massachusetts & $\begin{array}{l}\text { Variant with pyriform, rather than } \\
\text { oblong-oval, fruit }\end{array}$ \\
\hline Round & US92-36 & Massachusetts & $\begin{array}{l}\text { Variant with presence of bloom on a } \\
\text { rounder berry }\end{array}$ \\
\hline Sterile & US92-62 & Massachusetts & $\begin{array}{l}\text { Identified as sterile variant of standard } \\
\text { 'Howes' }\end{array}$ \\
\hline WI & US88-65 & Wisconsin & DuBays Cranberry Co., Portage County \\
\hline \multicolumn{4}{|c|}{ Early Black accessions } \\
\hline NJ \#1 & US93-139 & New Jersey & $\begin{array}{l}\text { Chatsworth Cranberry Co., Bog B-9, } \\
\text { Burlington County }\end{array}$ \\
\hline $\mathrm{NJ} \# 2$ & US93-133 & New Jersey & $\begin{array}{l}\text { Variant with purple fruit from same } \\
\text { planting as Early Black-NJ \#1 }\end{array}$ \\
\hline NJ \#3 & US93-129 & New Jersey & $\begin{array}{l}\text { Haines and Haines, Inc.; Bog 1; } \\
\text { Burlington County }\end{array}$ \\
\hline NJ \#4 & US93-135 & New Jersey & $\begin{array}{l}\text { Haines and Haines, Inc.; Bog 2; } \\
\text { Burlington County }\end{array}$ \\
\hline $\mathrm{NJ} \# 5$ & US94-9 & New Jersey & Rutgers experimental bog \\
\hline WI & US88-18 & Wisconsin & DuBays Cranberry Co., Portage County \\
\hline MA \#1 & US92-55 & Massachusetts & $\begin{array}{l}\text { MA Cranberry Research Center, main } \\
\text { plot }\end{array}$ \\
\hline MA \#2 & US88-76 & Massachusetts & MA Cranberry Research Center, Sect.\#13 \\
\hline \multicolumn{4}{|c|}{ Searles accessions } \\
\hline WI & US88-33 & Wisconsin & DuBays Cranberry Co., Portage County \\
\hline Flat & US88-29 & Wisconsin & $\begin{array}{l}\text { Variant with flat calyx end, selected } \\
\text { by D. Boone }\end{array}$ \\
\hline
\end{tabular}

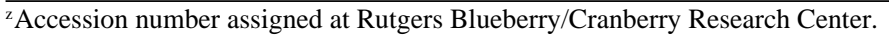


DNA fingerprints: 1) Early Black-MA \#1, McFarlin-OR, and McFarlin-WA \#1 and 2) McFarlin-NJ, Howes-WI, Howes-NJ \#3, and Howes-Round.

The 'Howes' group, composed of four representative clones and three clonal variants, was represented by five ssRAPD phenotypes. The identical ssRAPD profiles of Howes-WI, Howes-NJ \#3, and Howes-Round suggested that this profile is representative of a "typical" 'Howes'. An anomaly with respect to the 'Howes' consensus fingerprint was the presence of a New Jersey 'McFarlin' accession with an identical DNA fingerprint. Novy et al. (1994) identified this 'McFarlin' clone as possibly being a 'Howes' that was misclassified. The clustering of this 'McFarlin' clone with additional 'Howes' representatives supports the cultivar misclassification hypothesis. Based on their clustering, Howes-Sterile seemed to be related to the "typical" 'Howes', whereas Howes-NJ \#1 and \#2 from New Jersey growers' bogs seemed to be similar to one another, but were not closely aligned to the "typical" 'Howes'.

Of the six 'McFarlin' representatives analyzed, four unique ssRAPD phenotypes were identified. McFarlin-Bain and Rezin from Wisconsin could not be differentiated from one another. Another ssRAPD profile represented two 'McFarlin' clones from the Northwest (Oregon and Washington) and an 'Early Black' clone from Massachusetts, but McFarlin-WA \#2 seemed most closely related to 'Early Black' representatives from New Jersey and Massachusetts.

The seven representatives and one variant of 'Early Black' were characterized by five ssRAPD profiles. Early Black-NJ \#1, \#3, and \#5, and Early Black-WI had identical ssRAPD profiles and were thought to represent a "typical" 'Early Black' for New Jersey and Wisconsin. However, 'Early Black' clones from Massachusetts (the state of origin for 'Early Black') did not cluster with this group. Early Black-MA \#2 seemed to be most closely re- lated to a purple-fruited variant, Early BlackNJ \#2, but as previously indicated, Early BlackMA \#1 had a ssRAPD profile identical to the 'McFarlin' clones from Oregon and Washington.

The two 'Searles' accessions from Wisconsin differed from one another by 16 ssRAPDs. Seeming unrelated to one another based on their clustering, the Searles-Flat seemed to be most closely related to the "typical" 'Howes', while the other 'Searles' clustered with 'Howes' accessions from New Jersey.

AMOVA. The AMOVA among the 23 clones based on their original cultivar designation ('McFarlin', 'Howes', 'Early Black',

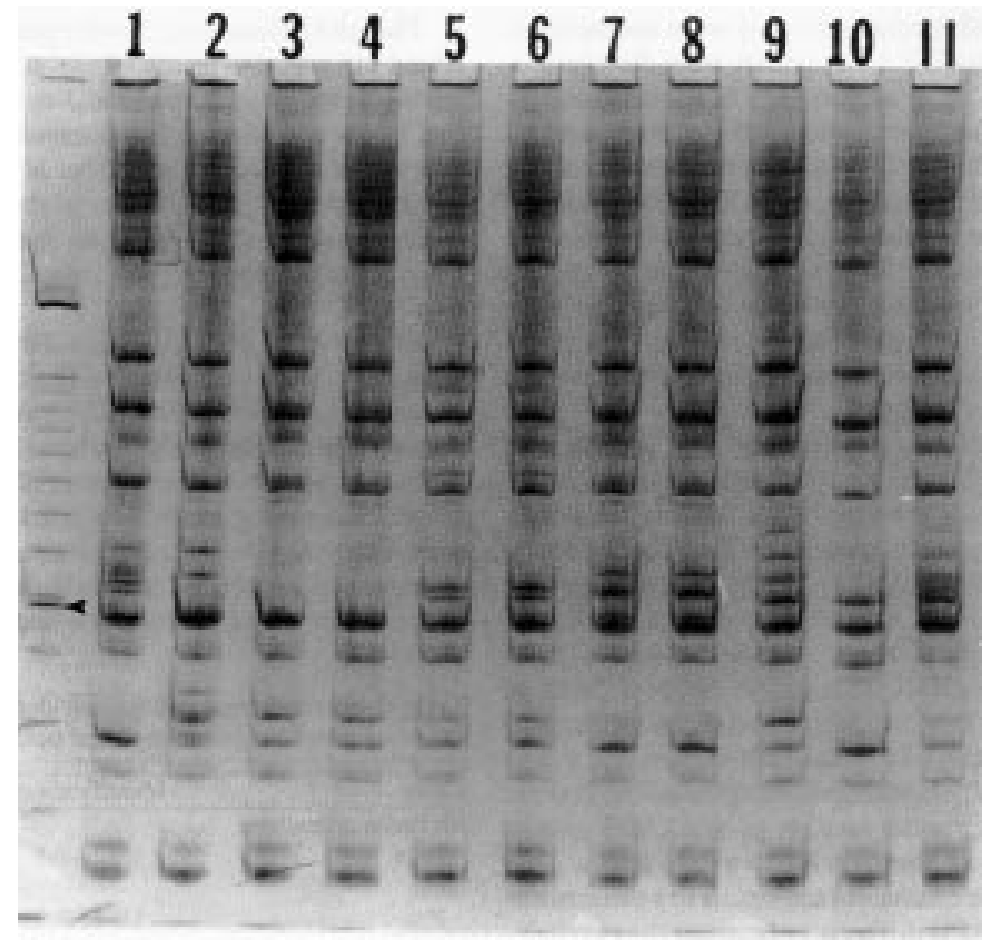

Fig.1. Silver-stained random amplified polymorphic DNA (ssRAPD) profiles for 11 cranberry clones generated by primer OPA-11. Lanes 1 to 3: 'McFarlin' clones Rezin, WA \#2, and WA\#1; Lanes 4 to 6: 'Early Black' clones MA\#1, NJ\#5, and WI; Lanes 7 to 9: 'Howes' clones NJ\#3, Round, and NJ\#2; Lanes 10 to 11: 'Searles' clones WI and Flat. Reproducibility of the ssRAPD profiles is evident in lanes 3 and 4, 5 and 6, and 7 and 8. Lanes 3 and 4 represent 'McFarlin' and 'Early Black' accessions with identical ssRAPD profiles; a situation also observed with the remaining 11 primers used in the analysis. Lanes 5 and 6 and 7 and 8 are examples of the reproducibility of ssRAPDs between 'Early Black' and 'Howes' accessions that had their DNA extracted at different times and with different protocols. Lane at left margin is 100-bp DNA ladder (Gibco BRL, Gaithersburg, Md.), with the darkest band (indicated by arrow) being $600 \mathrm{bp}$.

Table 2. Pairwise silver-stained, random amplified polymorphic DNA-marker differences between 23 cranberry clones.

\begin{tabular}{|c|c|c|c|c|c|c|c|c|c|c|c|c|c|c|c|c|c|c|c|c|c|c|c|}
\hline$\overline{\text { Cultivar }}$ & 1 & 2 & 3 & 4 & 5 & 6 & 7 & 8 & 9 & 10 & 11 & 12 & 13 & 14 & 15 & 16 & 17 & 18 & 19 & 20 & 21 & 22 & 23 \\
\hline 1 McFarlin-Bain & $*$ & & & & & & & & & & & & & & & & & & & & & & \\
\hline 2 McFarlin-Rezin & 0 & $*$ & & & & & & & & & & & & & & & & & & & & & \\
\hline 3 McFarlin-OR & 26 & 26 & $*$ & & & & & & & & & & & & & & & & & & & & \\
\hline 4 McFarlin-WA \#1 & 26 & 26 & 0 & $*$ & & & & & & & & & & & & & & & & & & & \\
\hline 5 McFarlin-WA \#2 & 21 & 21 & 21 & 21 & $*$ & & & & & & & & & & & & & & & & & & \\
\hline $6 \mathrm{McFarlin}-\mathrm{NJ}$ & 18 & 18 & 20 & 20 & 21 & $*$ & & & & & & & & & & & & & & & & & \\
\hline 7 Howes-NJ \#1 & 16 & 16 & 14 & 14 & 17 & 12 & $*$ & & & & & & & & & & & & & & & & \\
\hline 8 Howes-NJ \#2 & 12 & 12 & 16 & 16 & 21 & 14 & 10 & $*$ & & & & & & & & & & & & & & & \\
\hline 9 Howes-NJ \#3 & 18 & 18 & 20 & 20 & 21 & 0 & 12 & 14 & $*$ & & & & & & & & & & & & & & \\
\hline 10 Howes-Smalley & 20 & 20 & 18 & 18 & 21 & 12 & 14 & 16 & 12 & $*$ & & & & & & & & & & & & & \\
\hline 11 Howes-Round & 18 & 18 & 20 & 20 & 21 & 0 & 12 & 14 & 0 & 12 & $*$ & & & & & & & & & & & & \\
\hline 12 Howes-Sterile & 16 & 16 & 18 & 18 & 19 & 4 & 10 & 14 & 4 & 14 & 4 & $*$ & & & & & & & & & & & \\
\hline 13 Howes-WI & 18 & 18 & 20 & 20 & 21 & 0 & 12 & 14 & 0 & 12 & 0 & 4 & $*$ & & & & & & & & & & \\
\hline 14 Early Black-NJ \#1 & 18 & 18 & 18 & 18 & 25 & 12 & 10 & 14 & 12 & 16 & 12 & 12 & 12 & $*$ & & & & & & & & & \\
\hline 15 Early Black-NJ \#2 & 20 & 20 & 22 & 22 & 17 & 18 & 18 & 16 & 18 & 18 & 18 & 18 & 18 & 20 & $*$ & & & & & & & & \\
\hline 16 Early Black-NJ \#3 & 18 & 18 & 18 & 18 & 25 & 12 & 10 & 14 & 12 & 16 & 12 & 12 & 12 & 0 & 20 & $*$ & & & & & & & \\
\hline 17 Early Black-NJ \#4 & 17 & 17 & 23 & 23 & 26 & 19 & 19 & 13 & 19 & 21 & 19 & 21 & 19 & 21 & 17 & 21 & $*$ & & & & & & \\
\hline 18 Early Black-NJ \#5 & 18 & 18 & 18 & 18 & 25 & 12 & 10 & 14 & 12 & 16 & 12 & 12 & 12 & 0 & 20 & 0 & 21 & $*$ & & & & & \\
\hline 19 Early Black-WI & 18 & 18 & 18 & 18 & 25 & 12 & 10 & 14 & 12 & 16 & 12 & 12 & 12 & 0 & 20 & 0 & 21 & 0 & $*$ & & & & \\
\hline 20 Early Black-MA \#1 & 26 & 26 & 0 & 0 & 21 & 20 & 14 & 16 & 20 & 18 & 20 & 18 & 20 & 18 & 22 & 18 & 23 & 18 & 18 & $*$ & & & \\
\hline 21 Early Black-MA \#2 & 18 & 18 & 20 & 20 & 17 & 16 & 20 & 18 & 16 & 18 & 16 & 16 & 16 & 20 & 6 & 20 & 19 & 20 & 20 & 20 & $*$ & & \\
\hline 22 Searles-WI & 15 & 15 & 21 & 21 & 24 & 17 & 11 & 13 & 17 & 17 & 17 & 17 & 17 & 17 & 21 & 17 & 12 & 17 & 17 & 21 & 21 & $*$ & \\
\hline 23 Searles-Flat & 9 & 9 & 19 & 19 & 18 & 9 & 11 & 9 & 9 & 13 & 9 & 7 & 9 & 11 & 15 & 11 & 16 & 11 & 11 & 19 & 13 & 16 & $*$ \\
\hline
\end{tabular}


and 'Searles') was conducted to ascertain the variation between and within the four cultivars. Of the total genetic variability as assessed with ssRAPDs, $9.7 \%$ was attributed to variation between the four cultivar groups; the remaining $90.3 \%$ derived from variation within the cultivars.

Clone-specific markers. The genetic dissimilarity among clones of a given cultivar precluded identifying ssRAPD bands unique to a given cultivar. However, clone-specific bands were identified. Six of the 14 ssRAPD phenotypes could be distinguished from all others by the presence of a unique band(s) those being the McFarlin-Bain-Rezin, McFarlin-WA \#2, 'Howes' Smalley, Early Black-NJ \#2 and \#4, and the ssRAPD phenotype representing the (Early Black-NJ \#1, \#3, and \#5, and Early Black-WI) group.

\section{Discussion}

Silver-stained RAPDs have proven useful in assessing genetic diversity and identifying cranberry cultivars (Novy et al., 1994). They also have identified cases of apparent cultivar misclassification, leading to the conclusion that a cranberry cultivar may be represented by several genotypes. This conclusion was substantiated in this study by the intracultivar genetic variation found within accessions of the four major cranberry cultivars. Variability was observed even among cultivar accessions obtained from research and repository plantings, which might be assumed to have a high level of cultivar fidelity. The variable productivity often observed in commercial bogs of a cultivar may, therefore, have a genetic and environmental component, as was indicated by the divergent ssRAPD profiles between Early Black-NJ \#1 and \#2 that were obtained from the same bog site. Although this study was not intended as a survey of genetic variation within a bog site, subsequent ssRAPD analyses of commercial bogs of the cultivars Stevens and McFarlin have shown genetic variability within samples from the same bog (unpublished data). This being the case, ssRAPDs could be used in identifying genotype(s) with greater productivity, which could be used in the establishment of commercial plantings.

Within cranberry cultivars, there are at least three potential sources of genetic heterogeneity: 1) sexual seedling establishment, either from self- or cross pollinations; 2) native clone establishment from stolon encroachment or seed banks in cultivar bogs; and 3) cultivar misclassification. Evidence for volunteer seedling establishment is suggested in the close relatedness of Howes-Sterile to the "typical" 'Howes' (four-band differences), and Early Black-NJ \#2 and MA \#2 (six-band differences). In contrast, the 20-band differences between Early Black-NJ \#1 and \#2, two clones obtained from the same bog, provides evidence for native encroachment or cultivar misclassification within that bog.

Because cranberry is a clonally propagated species, growers and researchers often assume that a cultivar is represented by a single genotype. However, our study suggests that a cultivar may be represented by several genetically distinct and possibly unrelated clones, which would confound genetic vs. environmental sources of variation in research results

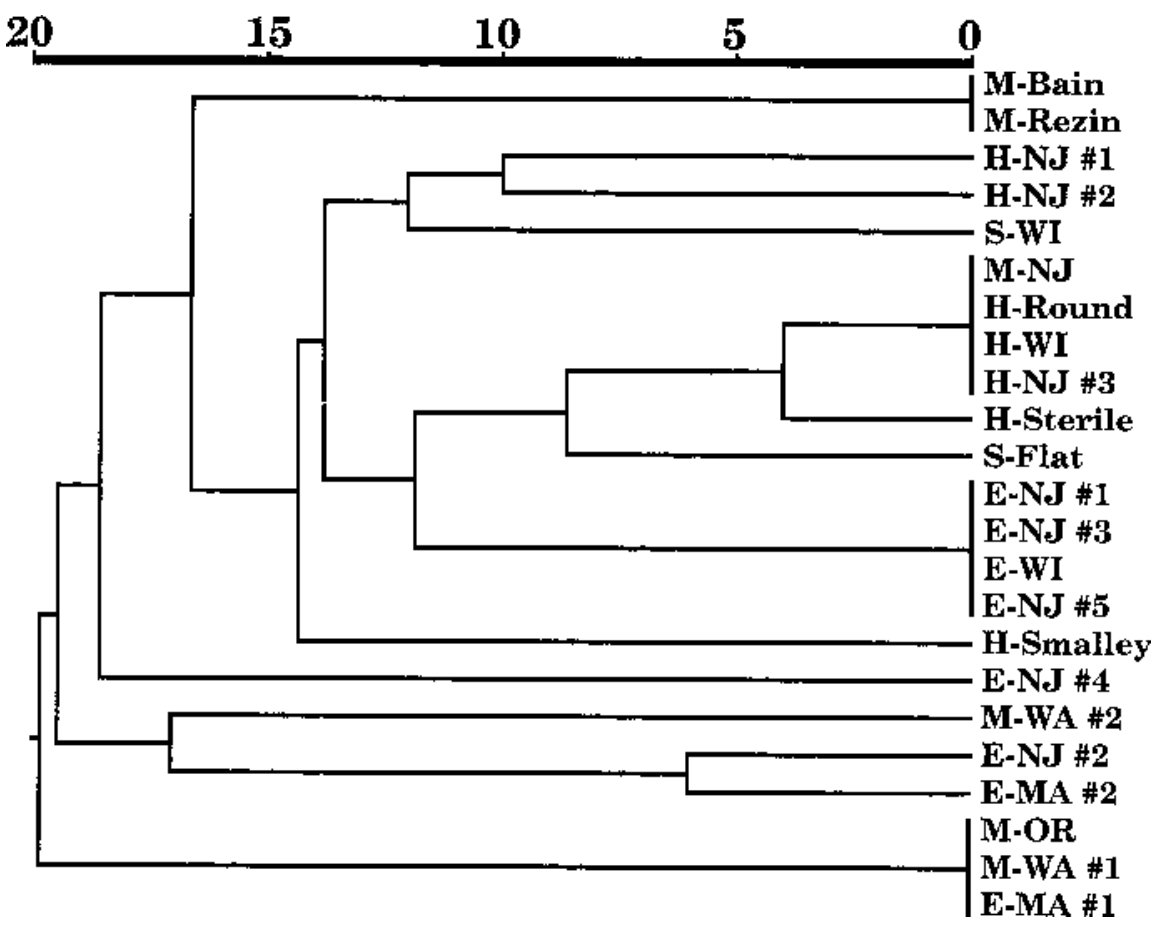

Fig. 2. Average-linkage dendrogram of clonal relationships as determined from silver-stained random amplified polymorohic DNAs (ssRAPDs). Distance units are based on the number of DNA band differences among cranberry clones. E, H, M, and S = 'Early Black', 'Howes', 'McFarlin', and 'Searles', respectively. A cophenetic correlation value of 0.91 indicated that there was a high level of agreement between the dendrogram and the original dissimilarity matrix. pertaining to that cultivar. A similar finding was reported by Kresovich et al. (1994) in clonally propagated vetiver grass; RAPD analysis found an accession of this clonally propagated crop to be composed of three genetically unique individuals. Iqbal and Rayburn (1994) also found intracultivar variability in sexually propagated rye (Secale cereale L.) following RAPD analysis. Under such circumstances, which DNA fingerprint accurately identifies a cultivar must be considered. As previously proposed (Novy et al., 1994), a ssRAPD survey of regional representatives of the variable cultivar could identify a consensus DNA fingerprint, as was done with 'Howes'. Such an approach, using samples obtained from a commercial tissue culture facility and commercial bogs throughout the United States, has yielded identical fingerprints for 'Stevens' and 'Pilgrim' (unpublished data). Identifying consensus fingerprints for these cultivars, using tissue collected from divergent bog and micropropagation environments, illustrates the reliability of the ssRAPD technique for cultivar identification.

The identical ssRAPD profiles of HowesRound and 'Howes', clones purported to be phenotypically divergent, might be explained by one of three hypotheses. 1) Somatic mutation in the 151-year-old 'Howes' resulted in an altered berry morphology. This genetic sport was identified and named Round 'Howes'. The ability to distinguish this clone from 'Howes' with ssRAPDs would not be expected, unless the mutations were linked to the loss or gain of a ssRAPD band. Similar findings were reported in potato (Solanum tuberosum L.) cultivars, whereby clonal variants differing in tuber pigmentation and vine vigor were indistinguishable from the original cultivar (Demeke et al., 1993) based on RAPD analysis. 2) No genetic differences exist. Instead, the phenotypic differences observed are environmentally induced. The morphological descriptors that distinguish among cranberry cultivars often are affected by environmental conditions. Round 'Howes', selected in 1910 (Dana, 1983), may have been a 'Howes' clone exhibiting a rounder berry with bloom due to environmental factors. The putative differences observed then were attributed to this variant of 'Howes' without any further substantiation of phenotype. In support of this hypothesis, M.N. Dana reported no bloom on Round 'Howes' berries during a Wisconsin field evaluation of the cultivar in 1988 (Dana, unpublished data). 3) Round 'Howes' is the selfed progeny of inbred 'Howes'. Cranberry has a high level of self-fertility (Sarracino and Vorsa, 1991). If 'Howes' is relatively inbred, then a seedling derived from a self-pollination would be expected to have a high probability of being similar, although possibly genetically distinct at a few loci. The number of ssRAPDs used in this study might have been insufficient to distinguish between the selfed progeny and the inbred parent.

Determining whether a putative genetic variant is the product of selfing or somatic mutation is not within the scope of this study. However, such a determination could be made 
if the degree of inbreeding within the cultivars was known. Information of this type could be obtained by analyzing the segregation of ssRAPD markers in the selfed progeny of cultivars.

Although a single fingerprint represented a group of 'Early Black' accessions, no Massachusetts clones were found in this group; this was unexpected because 'Early Black' originated in Massachusetts. Instead, the Massachusetts clones seemed to be unrelated to the New Jersey-Wisconsin group based on cluster analysis. Additional Massachusetts clones will need to be examined to determine whether the two Massachusetts clones analyzed in this study are truly representative of 'Early Black'.

'McFarlin' also showed no interregional consensus; instead, it was primarily represented by two genetically distinct groups, one from Wisconsin and the other from the northwestern states. The fingerprints for these two 'McFarlin' groups were the most divergent in our study; they differed by 26 ssRAPD bands. Genetic variability of this degree might account for lack of 'McFarlin' uniformity in berry size, shape, and shipping and keeping quality (Dana, 1983).

The two 'Searles' clones examined in this study differed from one another by 16 bands. A preliminary examination of an additional three 'Searles' clones has shown each of them to have their own unique ssRAPD profiles that differ from those of Searles-WI and SearlesFlat (unpublished data).

Consensus fingerprinting also has proved useful in establishing the true identities of three cranberry clonal selections of 'Early Red', 'McFarlin', and 'Howes' that were found to have identical ssRAPD profiles (Novy etal., 1994). The 'McFarlin' and 'Howes' clones from that study were designated as McFarlinNJ and Howes-NJ \#3 in our study. These two clones again were found to have DNA fingerprints identical to one another and to two other clonal representatives of 'Howes'. On the basis of this grouping, it seems that the 'Early Red' and 'McFarlin' in the first study were actually 'Howes' that had been misclassified.

Silver-stained RAPDs provide molecular markers in cranberry that can be used effectively to assess genetic diversity within and among cranberry cultivars. The reproducibility of the ssRAPD profiles is evident in those cases where accessions of a given cultivar showed identical ssRAPD profiles-an expected outcome in this asexually propagated crop. Such a consensus fingerprint, common to regional representatives of a cultivar, can be viewed as representative of that cultivar. The extreme genetic variability within the four cultivars analyzed in this study illustrates the confusion present in cranberry with respect to cultivar identity.

\section{Literature Cited}

Caetano-Anollés, G., B.J. Bassam, and P.M. Gresshoff. 1991.DNA amplification fingerprinting: A strategy for genome analysis. Plant Mol. Biol. Rptr. 9(4):292-305.

Caetano-Anollés, G., B.J. Bassam, and P.M. Gresshoff. 1992. DNA amplification fingerprinting with very short primers, p. 18-25. Proc. Applications RAPD Technol. Plant Breeding, Joint Plant Breeding Symp. Ser., Crop Sci. Soc. Amer., Amer. Soc. Hort. Sci., and Amer. Genet. Assn., Minneapolis.

Dana, M.N. 1983. Cranberry cultivar list. Fruit Var. J. 37:88-95.

Demeke, T., L.M. Kawchuck, and D.R. Lynch. 1993. Identification of potato cultivars and clonal variants by random amplified polymorphic DNA analysis. Amer. Potato J. 70:561-570.

Eck, P. 1990. The American cranberry. Rutgers Univ. Press, New Brunswick, N.J.

Excoffier, L., P.E. Smouse, and J.M. Quattro. 1992.
Analysis of molecular variance inferred from metric distances among DNA haplotypes: Application to human mitochondrial DNA restriction sites. Genetics 131:479-491.

Heun, M. and T. Helentjaris. 1993. Inheritance of RAPDs in $\mathrm{F}_{1}$ hybrids of corn. Theor. Appl. Genet. 85:961-968.

Huff, D.R. and J.M. Bara. 1993. Determining genetic origins of aberrant progeny from facultative apomictic Kentucky bluegrass. Theor. Appl. Genet. 87:201-208.

Huff, D.R., T.E. Bunting, and K.A. Plumley. 1994. Use of random amplified polymorphic DNA markers for the detection of genetic variation in Magnaporthe poae. Phytopathology 84:13121316.

Huff, D.R., R. Peakall, and P.E. Smouse. 1993. RAPD variation within and among natural populations of outcrossing buffalograss (Buchloe dactyloides (Nutt.) Engelm.). Theor. Appl. Genet. 86:927-934.

Iqbal, M.J. and A.L. Rayburn. 1994. Stability of RAPD markers for determining cultivar specific DNA profiles in rye (Secale cereale L.). Euphytica 75:215-220.

Kresovich, S., W.F. Lamboy, L. Rugang, J. Ren, A.K. Szewc-McFadden, and S.M. Bliek. 1994. Application of molecular methods and statistical analyses for discrimination of accessions and clones of vetiver grass. Crop Sci. 34:805809.

Novy, R.G., C. Kobak, J. Goffreda, and N. Vorsa. 1994. RAPDs identify varietal misclassification and regional divergence in cranberry (Vaccinium macrocarpon Ait.). Theor. Appl. Genet. 88:1004-1010.

Rowland, L.J. and B. Nguyen. 1993. Use of polyethylene glycol for purification of DNA from leaf tissue of woody plants. BioTechniques 14(5):735-736.

Sarracino, J.M. and N. Vorsa. 1991. Self and cross fertility in cranberry. Euphytica 58:129-136.

Stewart, C.N., Jr., and L.E. Via. 1993. A rapid CTAB DNA isolation technique useful for RAPD fingerprinting and other PCR applications. BioTechniques 14(5):748-750. 